\title{
Implementation of FPGA Based Hybrid Power Generator for PV and Wind Grid Applications
}

\author{
T. S. Balaji Damodhar1*, Dr. A. Senthil Kumar² \\ ${ }^{1}$ Anna University, Chennai, India \\ ${ }^{2}$ Department of Electrical and Electronics Engineering, Velammal Engineering College, Surapet, India \\ Email: balajidamodhar@gmail.com, vastham@gmail.com
}

How to cite this paper: Damodhar, T.S.B. and Kumar, Dr.A.S. (2016) Implementation of FPGA Based Hybrid Power Generator for PV and Wind Grid Applications. Circuits and Systems, 7, 4280-4290. http://dx.doi.org/10.4236/cs.2016.713350

Received: May 6, 2016

Accepted: May 20, 2016

Published: November 30, 2016

Copyright $\odot 2016$ by authors and Scientific Research Publishing Inc. This work is licensed under the Creative Commons Attribution International License (CC BY 4.0).

http://creativecommons.org/licenses/by/4.0/

\begin{abstract}
This paper deals with implementation of Sinusoidal Pulse-Width-Modulation (SPWM) for a single-phase hybrid power filter generator for Photovoltaic (PV) and wind grid applications. Using policy iteration algorithm, an improved variable step-size perturbation and observation algorithm is contrived and it is implemented proficiently using a hard-ware description language (VHDL) (Very High Speed Integrated Circuit Hardware Description Language). Subsequently, the new generated grid source supplements the existing grid power in rural houses during its cut off or restricted supply period. The software is used for generating SPWM modulation integrated with a solar-power \& wind power grid system which is implemented on the Spartan 3 FPGA. The proposed algorithm performs as a conventional controller in terms of tracking speed and mitigating fluctuation output power in steady state operation which is shown in the experimental results with a commercial PV array and HPW (Height Weight Proportional) show. Simulation results demonstrate the validity with load of the proposed algorithm.
\end{abstract}

\section{Keywords}

Sinusoidal Pulse Width Modulation (SPWM), Hybrid Inverter, VHDL, PV \& Wind System, FPGA-Spartan 3

\section{Introduction}

The basic requirement of the electrical energy is incessantly growing in consistent with the rapid growth of population and the increasing usage of the electrical gadgets. Diminishing trend of raw material resources has made the conventional grid supply standstill and inert in the grid connected areas. The further extension of convention grid supply is not possible due to various technical, political and economic reasons. 
Owing to the excess energy demand, alternative renewable energy sources like solar/ wind etc. are being used with energy storage device i.e. Battery which works as a standalone power source or in sharing mode with Grid or DG power source. Between the two sources, solar energy is highly preferred because it is easily available in every part of the country where as wind energy is restricted only to the coastal area. A hybrid system structure is shown in Figure 1. A novel integration scheme for PV and wind system is proposed for both grid and rotor side power converters of doubly fed induction generator [1]. Hybrid systems for wind and PV with standalone system with PI controller are proposed [2]. Voltage variation in hybrid system is controlled using converter [3]. It proposes a hybrid system of wind and PV on sea oil wellhead electrification, optimizing the size of the systems [4]. Six arms for power conversion PV and wind turbine generator are proposed for grid systems [5]. High voltage gain grid connected PV system, because steady state model analysis was carried out [6]. Discrete optimization of cost function and balance of energy analysis is done for hybrid system [7]. A novel multiinput inverter for grid connected hybrid system is proposed to simplify power system to reduce cost [8]. PV system designed to meet the system reliability and power quality issues are discussed [9]. An isolated hybrid system employs a simple three-phase square wave inverter to integrate photovoltaic arrays [10]. Stand alone hybrid inverter for PV and wind system is designed and calculation of optimum size of PV array for the system is designed [11]. A simple numerical algorithm has been developed for generation unit sizing. It has been used to determine the optimum generation capacity and storage needed for a stand-alone, wind, PV, and hybrid wind/PV system [12]. Concerning the initial investment purely solar power converter usage is much expensive and voltage control can be obtained by acting on the impedance connected to the module terminations. In order to reach optimal conditions, a DC/DC converter is used which has to be properly controlled. On account of varying solar insulation, sun radiation and the limited available grid source especially in rural sector, the battery barely, find time to

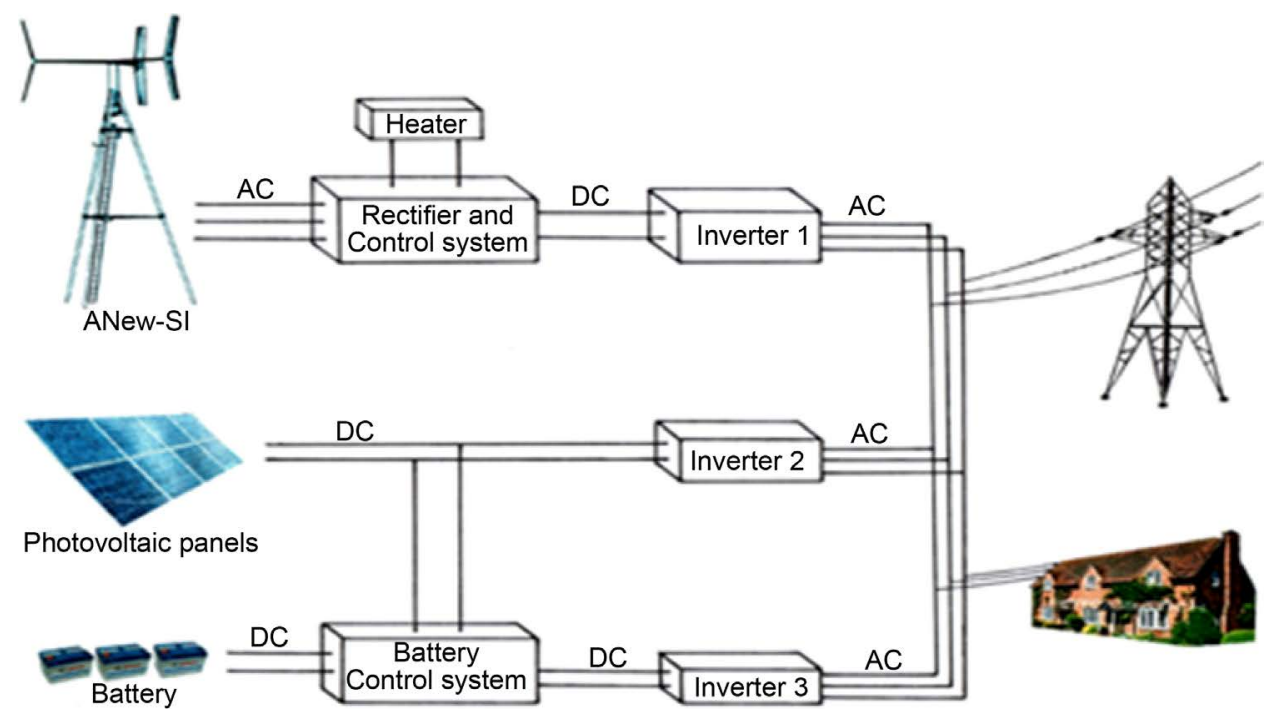

Figure 1. A hybrid system structure. 
get fully charged from a single PV source. Hence the solar power system needs to be integrated with supplementary additional DG back up sources for attaining 24 hour power supply. Adding more number of PV modules and battery bank, the system can work as a standalone power source in a grid deprived area in remote rural sectors. The optimal utilization of these sources is possible with efficient smart adaptive Power converter and adopting optimal load management. In the present paper, the Pulse width modulated (PWM) adaptive intelligent Power converter (inverter) the PWM pulses are directly generated using a new technique through software program coded with VHDL and downloaded in FPGA Spartan 3E starter kit to produce base drive signals for inverter power device. The FPGA VLSI technology offers a fast system with many more advantages as compared to other conventional technology etc. The software program can easily be changed to optimize and control the inverter parameters like frequency, voltage amplitude, number of PWM pulses in half cycle etc, without changing the hardware circuit.

\section{Hybrid System Modelling PV System}

The system works under three modes of operation namely:

$>$ Charging Mode (PV/Grid during sun hour available Period);

$>$ Inverting Mode (Grid Cut off or restricted (load shedding) Period).

The operation is controlled optimally (during the period when the system does not support to deliver power to load).

The Simulink structure of PV module is shown in Figure 2. Obtaining input energy through PV source during sun-hour, the battery is charged more than $12 \mathrm{~V}$ to $13.4 \mathrm{~V}$ which is the cut off limit. In case of low radiation or cloudy period, the charging is shared

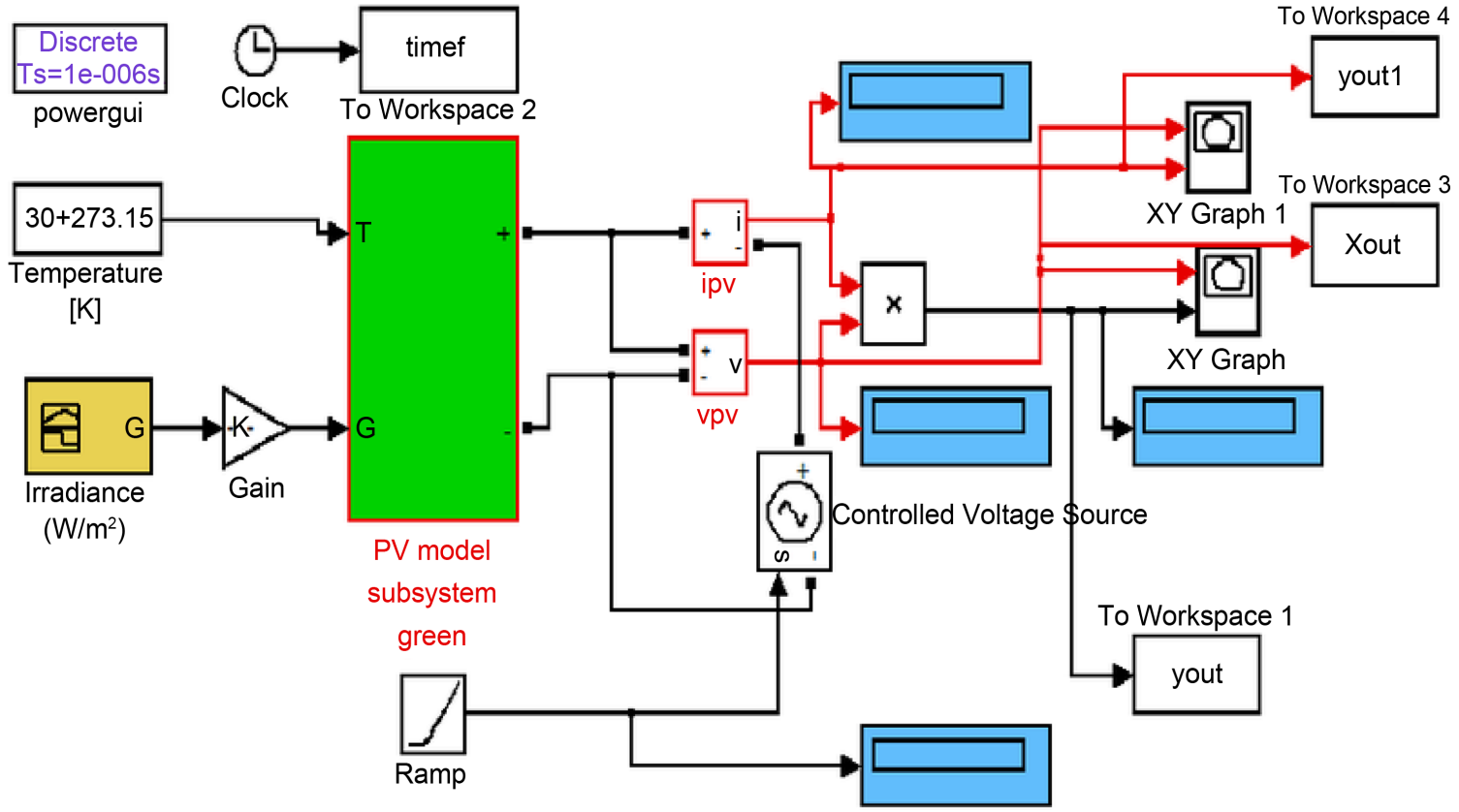

Figure 2. Simulink structure of PV module. 
proportionately with the grid/windmill source using time regulator circuit through sinusoidal PWM bi-directional inverter for meeting the required end user load energy demand. The typical characteristics of PV array are shown in Figure 3 and Figure 4.

$>$ Windmill mode (the power is generated from the wind turbo which has higher harmonics level. Thus, harmonics level is reduced and it is converted from AC to $\mathrm{DC})$.

Typical Characteristics of a PV array.

\section{Wind System}

Figure 5 shows a complete Simulink structure of wind system. The wind power driven generators like squirrel cage induction generator based of the wind speed versus wind

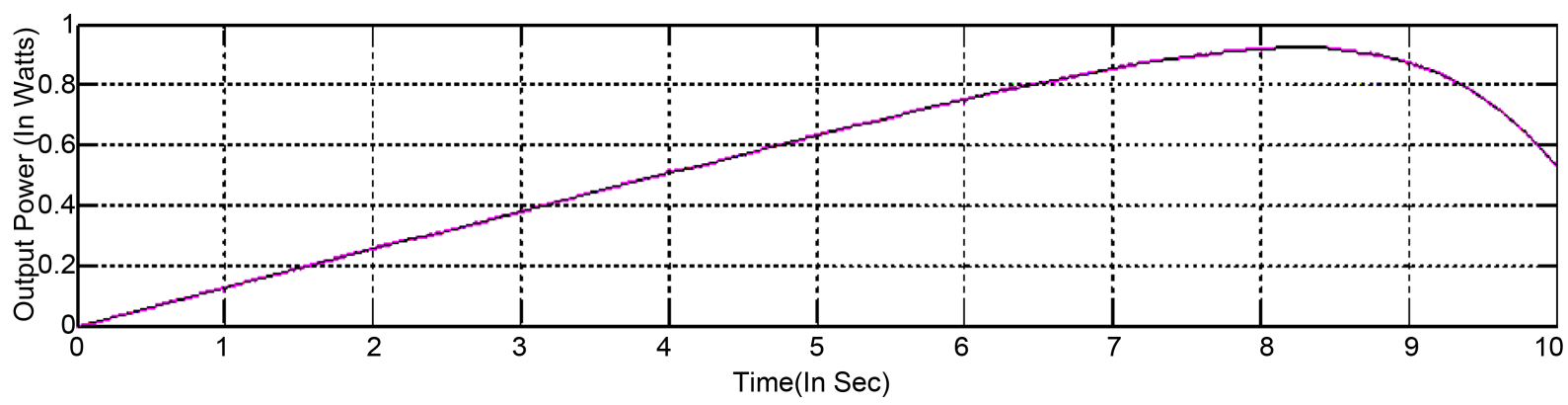

Figure 3. Output power of solar photovoltaic module.

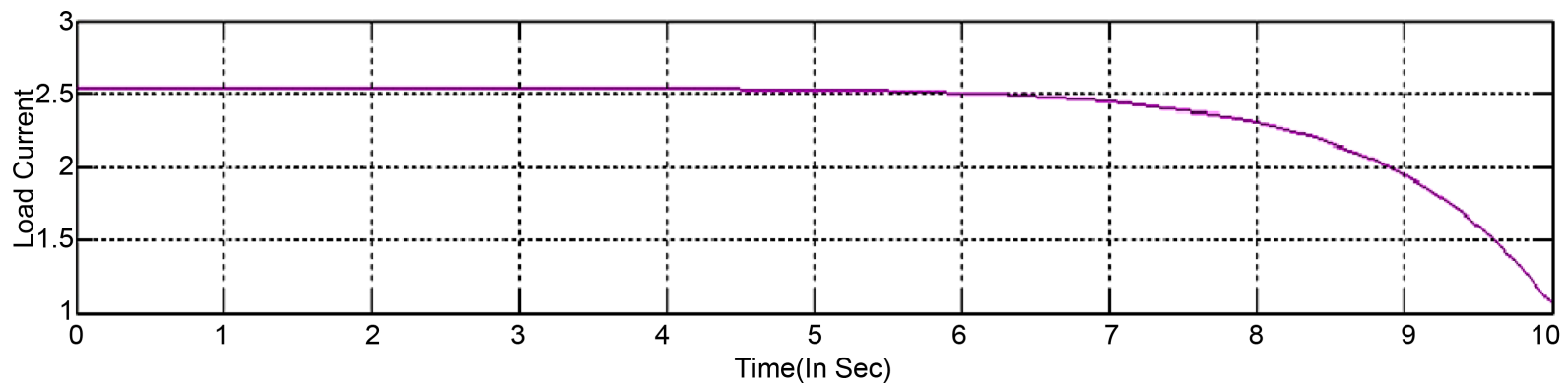

Figure 4. Load current of solar photovoltaic module.

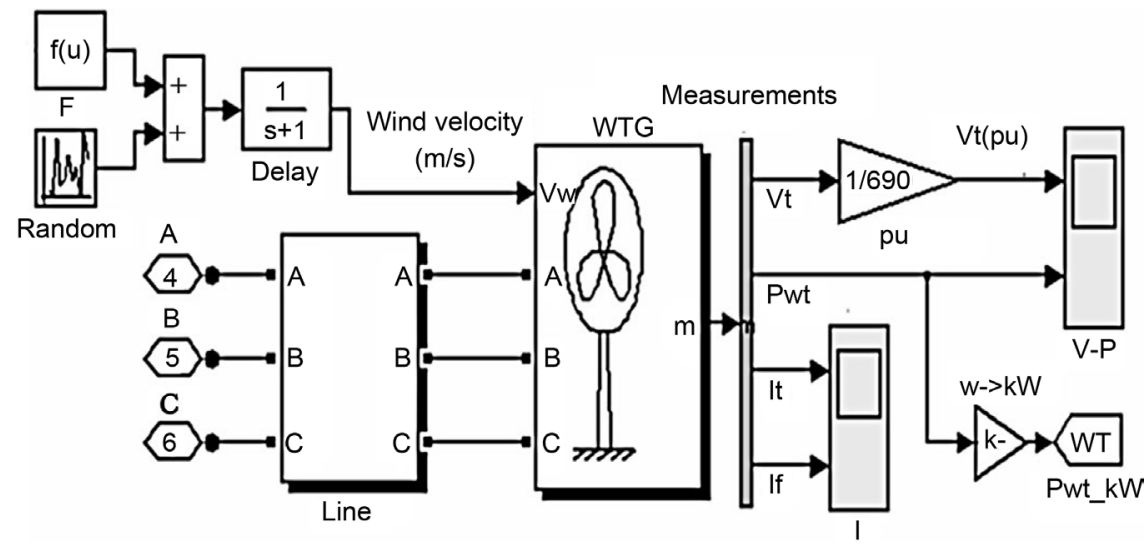

Figure 5. Simulink structure of wind system. 
turbine the output power obtained as,

$$
P_{w t}=\frac{p \cdot A}{2} V_{\text {wind }}^{3}
$$

The mathematical relation for mechanical power extraction form the wind turbine can be expressed as

$$
P_{m}=C_{p}(\lambda, \beta) \cdot P_{w T}
$$

where $\lambda$ : tip speed ratio;

$\beta$ : Blade pitch angle degree;

$C_{p}(\lambda, \beta):$ performance coefficient of the turbine.

Figure 6 shows the turbine power characteristics.

\section{Variable Step-Size Perturbation and Observation Algorithm}

As the paragraph's title suggests, perturbing control variable voltage operates $\mathrm{P} \& \mathrm{O}$ algorithm and comparing the instantaneous grid output power after perturbation with previous outputs. In a controller using $\mathrm{P} \& \mathrm{O}$ method the adjustment of the operating point is achieved by changing the reference voltage of the controller. However, the adjustment can be made through the duty ratio. Note that $V(k)$ and $P(k)$ are output voltage and the power of the grid which is calculated from $V(k) \times I(k)$ at time $k$, respectively.

To achieve faster Height Weight Proportional response and more accurate MPP under dynamic environment, variable step-size voltage has to be merged with source.

$$
A D(k)=a_{0} \cdot 8(p(k))
$$

\section{Proposed Hybrid System}

Hybrid system is an integrated system which can be operated under changing natural conditions to provide a quality power supply to remote areas. The system utilizes different renewable energy sources altogether such as solar energy, wind energy, or micro hydropower. The profuse energy is available in renewable sources which can be harnessed and converted as electricity in a sustainable way to supply the necessary power to the people without accessing the electricity grid. On accessing the hybrid system in

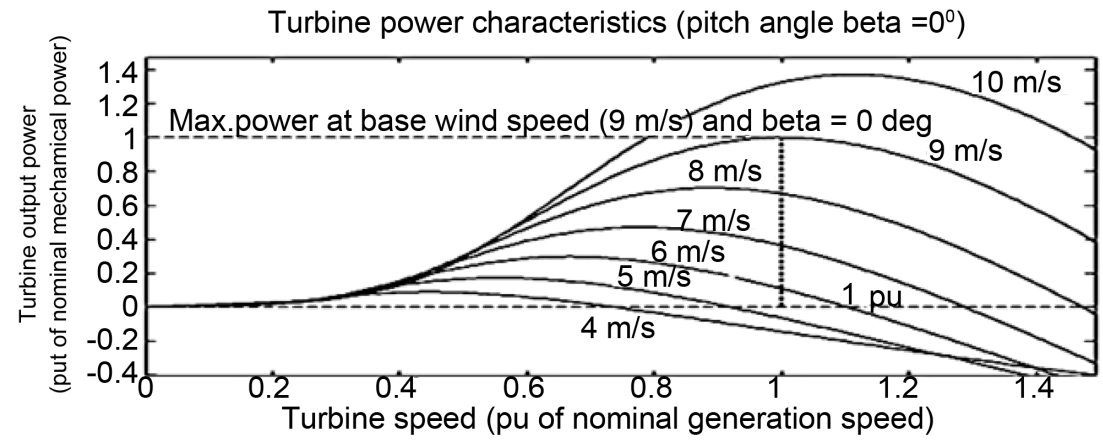

Figure 6. Turbine power characteristics. 
remote areas, the cost of transported fuel can be avoided and it has less effect on climate change and global warming. According to the availability of renewable energy sources in daily and seasonal patterns, the standalone power systems using renewable energy has difficulties in regulating the output power based on the load demand. The power generated from renewable energy sources becomes more reliable and affordable when it is combined with generated conventional power which will enable the hybrid system to produce sustainable targeted power supply. A schematic of a solar PV-Wind hybrid system is presented in Figure 1. Comparing to the stand-alone system, this hybrid system has an ability to provide 24-hour grid quality electricity to the load which has better efficiency, flexibility of planning and environmental benefits.

\section{Simulation of Hybrid Power System}

Different types of hybrid power systems namely wind/FC/UC-based hybrid power generation system, solar cell/wind turbine/fuel cell hybrid power system, and solar cell (SC), wind turbine (WT), fuel cell (FC) and ultra capacitor (UC) systems are modeled and simulated using SimPowerSystems and Matlab/Simulink software packages. The objective of these simulations is to achieve minimum or negligible fluctuation of power output from hybrid power system with respect to changes in load and environmental conditions. An integrated hybrid power system consisting of a photovoltaic energy system and a wind power system was modeled along with an optimized digital control system design and rapid Field Programmable Gate Array (FPGA) prototyping with the digital controller as shown in Figure 7. The above system was compared with a system already simulated using Matlab/Simulink software simulated three stand-alone solar photo-voltaic (SPV) hybrid power systems using different energy storage technologies

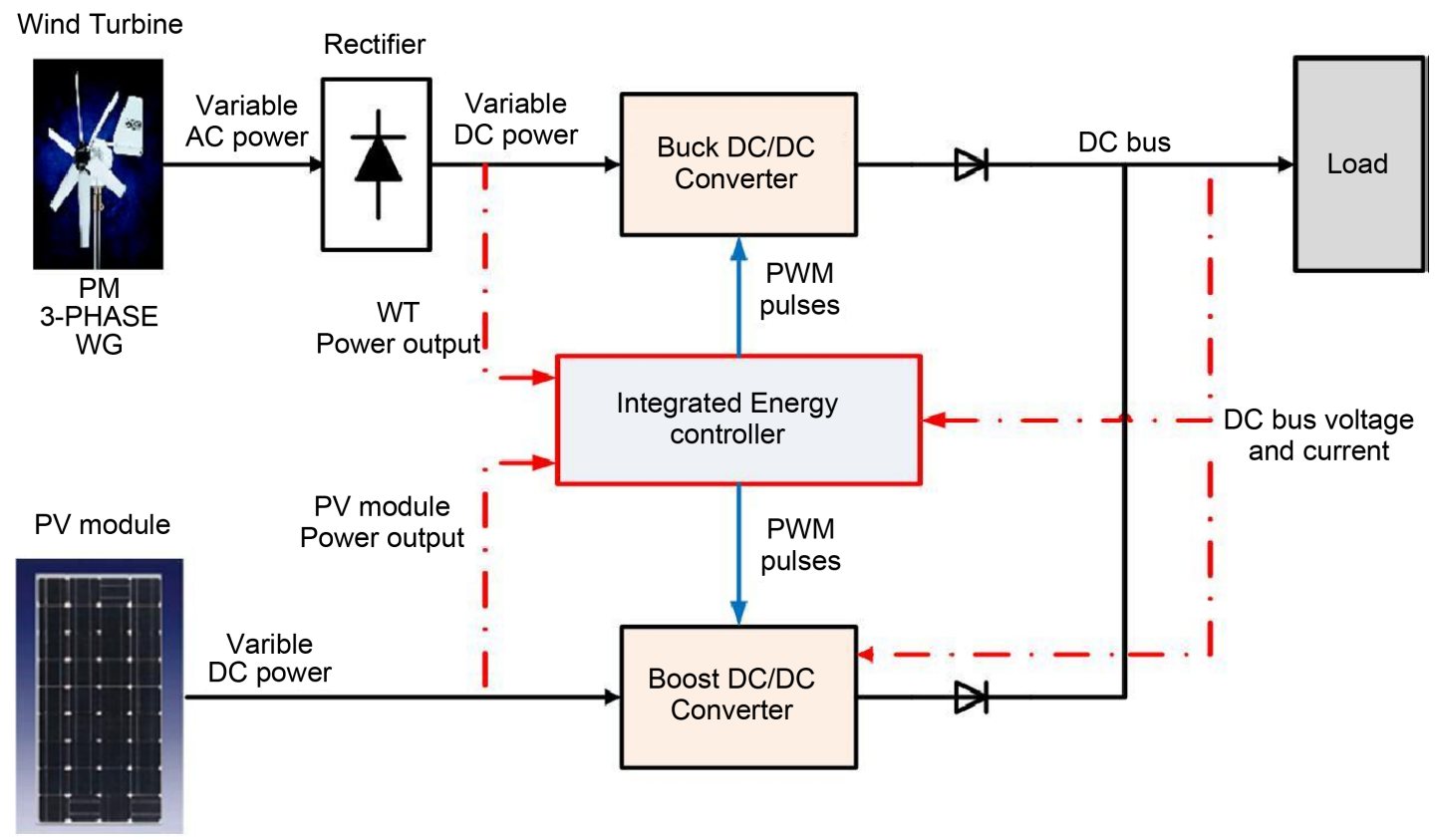

Figure 7. Proposed hybrid system. 
i.e. SPV-Battery system, SPV-Fuel Cell (FC) system and SPV-FC-Battery system using HOMER software. The purpose of this simulation was to optimize, analyze and compare the effect of Maximum Power Point Tracker (MPPT) technology system on the three SPV systems using different storage technologies. It has been found from simulations that SPV-FC-Battery hybrid system has least system cost and best energy consumption pattern compared with the other two single storage systems. Sousa et al. have modeled and simulated systems of multiple sources of energy (SMSEs) using formalism Differential Hybrid Petri Nets. Petri Nets is used to describe large number of system models, analyze techniques and graphical representations considering local states and local actions with their mutual relationships. They modeled discrete events dynamic, continuous dynamics considering their mutual dependence and did formal verification.

A simulation model of combined biogas, bio-ethanol and protein fodder co-production in organic farming has been developed to analyze the scope of renewable energy production in sustainable agriculture. Site specific, load and resource dependent optimization of hybrid energy system, using MATLAB 12.0 software version, reveals that stability and continuous power supply property of hybrid energy system is better than any single renewable energy system. A renewable energy based hybrid (wind and solar) power system is modeled. The combined uncertainty in availability of energy, the load variation and compared the effects of different combinations of energy storage on load variation for adequate and reliable energy supply is also modeled. A simulation model was developed to optimize the system design of a hybrid power system with MATLAB software. Different types of hybrid generating systems with storage technology, namely photovoltaic system with diesel generator, wind power solar PV/hydrogen fuel cell energy system and the grid-connected hybrid generation system consisting of fuel-fired generators (FFGs), wind turbine generators (WTGs), PV panels (PVs), and storage batteries (SBs) are simulated by time-series based optimized simulation, MATLAB software and multi-objective particle swarm optimization algorithm coded language for design optimization, cost optimization considering system constraints and performance prediction.

The transient analysis of integrated generation systems (IGSs) due to sudden changes of load, parallel operation of rotating machines and static converters having different characteristics is simulated using a simulation package called Combined Multiple Renewable Energy Sources System Simulator (CMRESSS) to calculate the electrical and mechanical parameters during normal or abnormal conditions. This simulation package which runs in MS-DOS environment has been developed and tested by performing several simulations. A hybrid wind-dump load generation system under changing operating conditions and a wind-battery hybrid system is simulated and modeled by Takagi-Sugeno (TS) fuzzy model, linear quadratic regulator (LQR) and sliding mode nonlinear control design technique. The TS fuzzy based controller is compared with a proportional-integral (PI) controller and the simulation results show that the proposed controller provide less fluctuations in power output during wind speed and load variation disturbances than the PI controller in wind-hybrid power generation system. The 
results show (Figure 8 \& Figure 9) that the output fluctuations are much less and performance behavior is smoother for wind-battery.

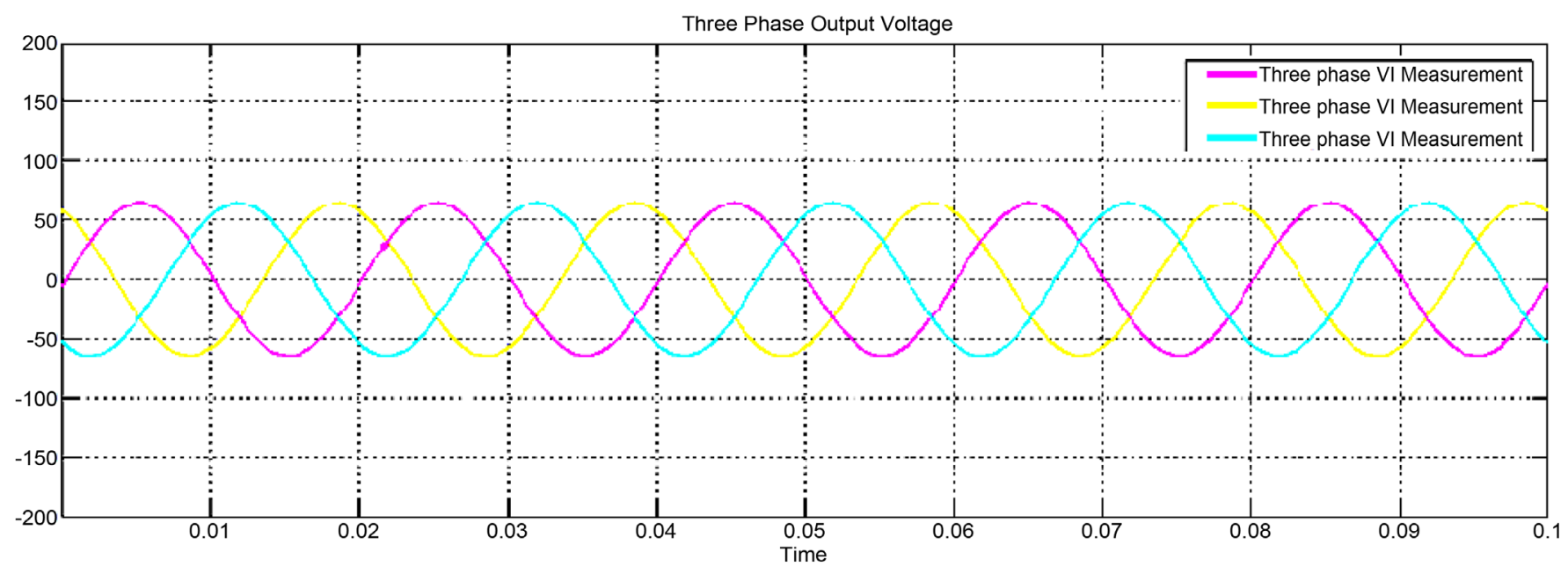

Three Phase Output Current

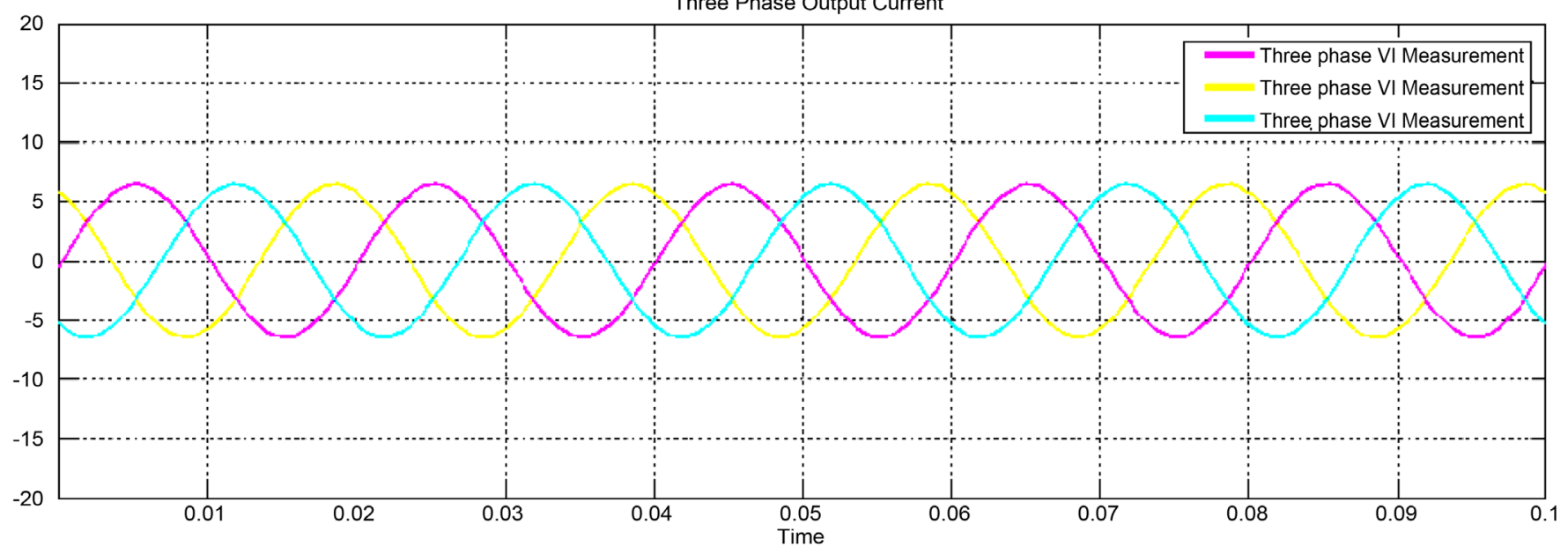

Figure 8. Output load and voltage wave form for hybrid systems.
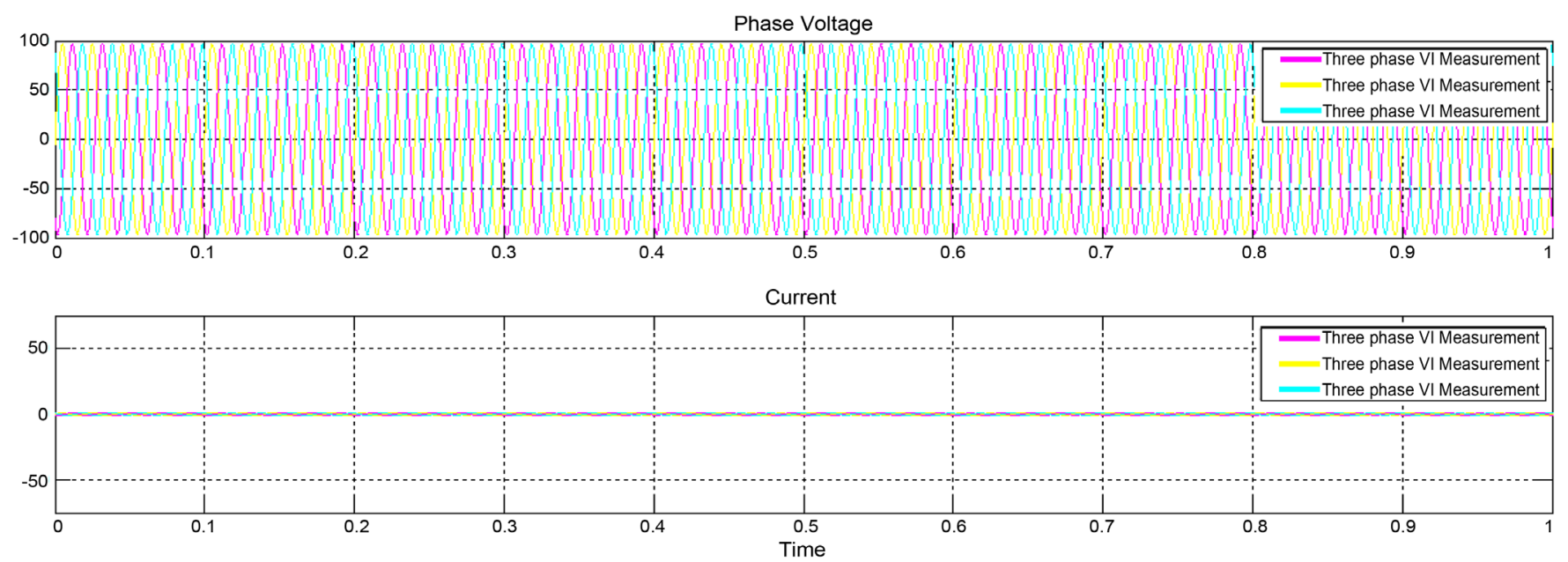

Figure 9. Inter harmonics negligible. 
Hybrid system. An operation and control methodology of a three phase, four wire voltage source inverter (VSI) under unbalanced voltage conditions for a hybrid power system is modeled. The control techniques are applied by dividing the supply voltages and currents into positive, negative and homo-polar sequence components which are controlled independently using different synchronously rotating reference frame systems. So the output voltage is unaffected by load imbalances. Windmill turbo simulated the effect of wind speed and tide variation on the output power of a grid connected wind/tidal hybrid system. They have simulated the system after incorporating a dynamic voltage regulator (DVR) controlled by a tri-loop dynamic error driven PI controller. Comparing the simulated results with that of the network without DVR, the power output and voltage variation is reduced. For instance, in isolated small islands, a standalone renewable energy based power supply system is simulated by fuel cell generators and wind turbine generators. The total output power meets the total load demand, no separate batteries are required and the system efficiency is improved. An object oriented simulation model using Any Logic simulation software has been developed to design micro grid hybrid system. Any Logic is a hybrid simulation software which integrates discrete event, system dynamics, and agent based models to model systems.

\subsection{Harmonic Occurrence}

Using MATLAB (Version-12.0) software, the harmonic occurrence is analyzed. The computed value of the expressions in \% for $\mathrm{N}$ number is shown in Figure 4. Harmonic currents make main issues in grid part. It poses a challenge in the measurement of power quality and it requires great accuracy. When Harmonics occur in load, it is observed through intelligent controller and matched with available integrated grid power.

\subsection{Simulation Setup}

The wind farm has a wind turbine unit. The unit consists a wind generator of $440 \mathrm{~V}$ rating. Using a step up transformer, the generated voltage of each wind turbine unit is stepped up to $440 \mathrm{~V}$. Through a $1 \mathrm{~km}$ transmission line, the power from the step up transformer is transmitted to the grid. The proposed photovoltaic system is integrated with the wind energy system to form the hybrid system is shown in Figure 2. The PVA model created using Simulink incorporates the required filters and load. A stable voltage is maintained by the filter which has been connected to the load. It is made up of a $\mathrm{R}-\mathrm{L}$ and parallel $\mathrm{C}$ components. The PV system has a total of $8 \mathrm{PV}$ cells connected in series. Using variable blocks, Temperature and irradiance are represented which can be adjusted for different scenarios. The described solar PV system and wind farm are integrated and connected to a common grid system to form a hybrid renewable energy system to ensure continuous power flow to the grid. The block diagram of the proposed hybrid renewable energy system is shown in Figure 3. The proposed hybrid system has a wind turbine and a photovoltaic array which are main energy sources. To connect the PV system to the grid, the needed adaptation is, to adjust the DC bus voltage to the 
characteristics of the conventional or isolated grids. Both energy sources are connected in parallel to a common PWM voltage source inverter through their individual AC/DC and $\mathrm{DC} / \mathrm{DC}$ converters. A AC/DC converter (rectifier) is used to transform the 3 phase variable frequency wind turbine, $\mathrm{AC}$ power is converted into variable DC power, and a $\mathrm{DC} / \mathrm{DC}$ converter is used to control variable power DC from the solar array and produce DC power using a PWM voltage source to balance the necessary power required from the inverter onto the DC bus. Even though every source has its individual controller mechanism, they share a similar configuration. The VLSI based fuzzy logic controller controls the constant voltage level required from the load through the PWM controller of each converter. The wind turbine and the photovoltaic array voltage are controlled based on the error signal. The error is fed into the controller, to generate the pulses (switch status) for the $\mathrm{dc}$-dc converter. The results show that the load receives a constant power supply from the two sources.

\section{Conclusion}

The generated PWM from FPGA renders pulse to hybrid grid. The required power to the hybrid is generated from DC source. DC source consists of wind turbo and PV array. Relying to the wind speed, wind turbo is rotated and power is generated. Harmonics level is reduced in the generated power and it is converted from AC to DC. The generated DC is running through hybrid and is stored in the rechargeable battery. The PV array consists of eight PV panels. The generated power from eight PV panels is combined and boosted DC to DC and it is stored in the rechargeable battery. The stored power can be inverted and used in the load. The specified process has been contrived in the simulation.

\section{References}

[1] Wandhare, R.G. and Agarwal, I. (2015) Novel Integration of a PV-Wind Energy System with Enhanced Efficiency. IEEE Transactions on Power Electronics, 7, 3638-3649.

[2] Sakthivel, B.K. and Devaraj, D. (2015) Modelling, Simulation and Performance Evaluation of Solar PV-Wind Hybrid Energy System. IEEE Electrical, Electronics, Signals, Communication and Optimization, 24-25 January 2015, Visakhapatnam, 1-6.

[3] Nair, N.R. (2014) Mabel Ebenezer Operation and Control of Grid Connected Wind-PV Hybrid System. IEEE Advances in Green Energy (ICAGE), 17-18 December 2014, 197-203.

[4] Grouz, F. and Sbita, L. (2014) A Safe and Easy Methodology for Design and Sizing of a Stand-Alone Hybrid PV-Wind System. IEEE Electrical Sciences and Technologies in Maghreb, 3-6 November 2014, 1-8. https://doi.org/10.1109/cistem.2014.7077043

[5] Chiang, H.C., Ma, T.T., Cheng, Y.H. and Chang, J.M. (2010) Design and Implementation of a Hybrid Regenerative Power System Combining Grid-Tie and Uninterruptible Power Supply Functions. IET Renewable Power Generation, 4, 85-99. https://doi.org/10.1049/iet-rpg.2009.0033

[6] Yang, B., Li, W.H., Zhao, Y. and He, X.N. (2010) Design and Analysis of a Grid-Connected Photovoltaic Power System. IEEE Transactions on Power Electronics, 25, 992-1000. https://doi.org/10.1109/TPEL.2009.2036432

[7] Mousavi Badejani, M., Masoum, M.A.S. and Kalanta, M. (2007) Optimal Design and Mod- 
eling of Stand-Alone Hybrid PV-Wind Systems. IEEE Power Engineering Conference, Australasian Universities, 1-6.

[8] Chen, Y.-M., Liu, Y.-C., Hung, S.-C. and Cheng, C.-S. (2007) Multi-Input Inverter for Grid-Connected Hybrid PV/Wind Power System. IEEE Transactions on Power Electronics, 22, $70-1077$.

[9] Giraud, F. and Salameh, Z.M. (2002) Steady-State Performance of a Grid-Connected Rooftop Hybrid Wind-Photovoltaic Power System with Battery Storage. IEEE Transactions on Energy Conversion, 16, 1-7.

[10] Daniel, S.A. and Ammasai Gounden, N. (2004) A Novel Hybrid Isolated Generating System Based on PV Fed Inverter-Assisted Wind-Driven Induction Generators. IEEE Transactions on Energy Conversion, 2, 416-422. https://doi.org/10.1109/TEC.2004.827031

[11] Borowy, B.S. and Salameh, Z.M. (2002) Optimum Photovoltaic Array Size for a Hybrid Wind/PV System. IEEE Transactions on Energy Conversion, 9, 482-488. https://doi.org/10.1109/60.326466

[12] Kellogg, W.D., Nehrir, M.H., Venkataramanan, G. and Gerez, V. (2002) Generation Unit Sizing and Cost Analysis for Stand-Alone Wind, Photovoltaic, and hybrid Wind/PV Systems. IEEE Transactions on Energy Conversion, 6 August 2002, 70-75.

Submit or recommend next manuscript to SCIRP and we will provide best service for you:

Accepting pre-submission inquiries through Email, Facebook, LinkedIn, Twitter, etc. A wide selection of journals (inclusive of 9 subjects, more than 200 journals)

Providing 24-hour high-quality service

User-friendly online submission system

Fair and swift peer-review system

Efficient typesetting and proofreading procedure

Display of the result of downloads and visits, as well as the number of cited articles

Maximum dissemination of your research work

Submit your manuscript at: http://papersubmission.scirp.org/

Or contact cs@scirp.org 